\title{
Human Germline Gene Therapy ${ }^{1}$
}

\author{
Torsten O. Nielsen* ${ }^{*}$ M.D.C.M., Ph.D.
}

The idea of human germline gene therapy introducing genetic changes into early embryos which become incorporated into all cells of the body and, as such, are passed on to future generations - has elicited considerable ethical, scientific, and political controversy. Technological advances have turned what until recently was fanciful science fiction into a theoretical and practical possibility. Human germline interventions raise unique ethical concerns which must be addressed, such as its possible use for eugenics. The basic technology of germline gene therapy is being successfully applied in animal experiments for the investigation of gene function, proving to be exceptionally valuable in dissecting the genetic controls of development and in creating models for the study of human diseases. However, while transgenic animal research provides a powerful tool for studying gene function, human germline gene therapy is unlikely ever to be a procedure with significant clinical utility, and is probably not worth pursuing, considering the danger posed by its comparative usefulness for eugenic enhancement. From a medical perspective, uses for this technology in the treatment of genetic disease are limited, and more efficient alternative procedures (such as preimplantation diagnosis followed by selective reimplantation) will likely become available.

\section{ETHICAL CONSIDERATIONS}

In the 1980s, initial discussion about human gene therapy sometimes evoked strong opposition, based on claims that it entails playing God, or violates "natural law" (1). A background paper submitted to the Canadian parliament stated bluntly that "there is a feeling among segments of the general public that the

*To whom correspondence should be addressed: Capital Health Region, Postgraduate Education Office, \#186 - 2334 Trent St., Victoria, British Columbia, Canada, V8R 4Z3 genetic manipulation of humans is simply not an acceptable activity" (2). However, the public is thought to dramatically overestimate the risks of that which is unfamiliar, hard to understand, or outside public scrutiny (3). Technophobia regarding human gene therapy has, to a degree, subsided, and the debate has evolved to focus more on the potential benefits of such treatment. A U.S. government poll in the late 1980s found that fully $84 \%$ of Americans supported the genetic manipulation of human cells to cure fatal genetic diseases (4).

Somatic cell gene therapy, for recognized genetic disorders, is broadly considered to be acceptable in principle, gaining the approval of all international policy bodies which have studied the issue (5) as it "poses no new ethical problems" (6), and is not morally different from, for instance, organ transplantation. Because safety and efficacy in humans is not fully established, somatic cell gene therapy is currently employed only under strict criteria (2); an example of a current protocol yielding encouraging results is the replacement of the adenosine deaminase gene in lymphocyte progenitor cells, to cure children of severe combined immunodeficiency (7). The acceptance of somatic cell gene therapy means that questions about germline gene therapy can focus on its unique and crucial differences: the effects are permanent and passed on to future generations who cannot give their consent, and human germline interventions are extremely difficult to study experimentally.

The major argument raised in favour of developing germline gene therapy derives from the ethical principle of beneficence (3): up to $2 \%$ of newborns suffer from some kind of genetic defect (5), including many of the

\footnotetext{
${ }^{1}$ See Commentary in Letters to the Editor (page 78)
} 
most miserable diseases known (8), such as LeschNyhan syndrome. Germline interventions may in some cases be the only way to prevent development of a genetic disease, furthermore, benefits would extend to future generations (9). A second important argument derives from the principle of liberty, holding that the majority who derive no benefits from this technology should not, in the name of "human dignity" or "integrity of the gene pool," curtail the specific interests of a minority seeking to cure genetic diseases without compelling cause (10).

The "ecological argument" has been put forward as an argument against germline gene therapy. It claims that the human gene pool, a product of thousands and millions of years of carefully balanced evolution, will potentially be weakened in unintended and unpredictable ways by germline gene therapy (11). For example, the loss of unrealized heterozygote advantages. However, as the Royal Commission on New Reproductive Technologies believes (5), the risks to the gene pool (usually raised by non-geneticists) are grossly exaggerated, considering its vast size and fluidity; individual tinkering by rarely-utilized technologies would have an insignificant impact. Furthermore, the impact would be far lower than modifications to the gene pool induced by pediatric therapy in general (12).

Of greater concern is the claim that germline gene therapy would open the door to enhancement engineering of the human genome for eugenic purposes, which is consistently cited as the major problem with this technology. Fears of possible eugenic uses of germline gene therapy are based upon both the recent past history of the Western world, and on persisting large-scale, sometimes state-sponsored, programs in developing countries (13). A 1987 U.S. government poll found that a shocking $44 \%$ of Americans approved of scientists changing the makeup of human cells to improve the intelligence level and physical characteristics that children would inherit (4).

Meanwhile, human embryo work has largely fallen into the hands of private fertility clinics (14) which would benefit financially by offering eugenic procedures to those able to afford it. Ethicists and government commissions have expressed unanimous opposition to enhancement engineering, arguing that it carries huge social risks for abuse of power, discrimination, and inequality (3). The line between clinically required therapy and eugenic enhancement can be fuzzy, whereas the line between germline and somatic gene therapy is clear, and considering that "it may be impossible, as a practical matter, to prevent these [germline gene therapy] techniques from being used for enhancement" (15), national commissions suggesting policy guidelines for research frequently draw the clearer line, banning germline experimentation, to prevent any chance of a progression to eugenic applications.

In response, it has been argued that germline genetic alterations are unlike classical eugenics, in that they eliminate defective genes rather than human beings (12), and that multifactorial traits like intelligence or attractiveness may never prove amenable to manipulation. More importantly, the eugenics argument presupposes a slippery slope, however, morally-relevant lines can be drawn to delineate acceptable versus unethical applications of the technology (16). To this end, Berger and Gert (6) define the term "malady" as a physical disorder which provides a direct challenge to the fundamental principles of benevolence and nonmaleficence, by imposing the universally-accepted evils of death, pain, or disability, precluding the freedom and pleasure available in life to the vast majority of other human beings. Relief of morbidity and mortality fall within the acceptable line, changing sex or increasing otherwise normal intelligence or height - decisions not based on medical need - would lie outside. Thus, the ethical line should be drawn to make therapy acceptable and enhancement unacceptable, rather than the current state permitting somatic manipulations but disallowing germline experiments (16).

Informed consent becomes a special problem with germline gene therapy, because it is impossible to obtain the direct consent of the embryo, or of future generations who will be affected (1). The way to tackle this problem, as suggested by the Inuyama Declaration of the Council for International Organizations of Medical Sciences, is to assume consent only in cases where genetic intervention would seem obviously acceptable to the affected future generations. However, procedures must first be refined and the actual risks to experimental subjects become more clear through ongoing, careful animal studies (10).

A last ethical issue integral to germline gene therapy arises because development of this technology necessitates experimentation on human embryos, and embryos will invariably be lost or sacrificed as part of the engineering procedure. To the extent that human embryos are assigned moral weight, they must be factored into the ethical deliberation, which therefore requires a more thorough understanding of the technical aspects of exactly how germline gene therapy would be accomplished.

\section{PRACTICAL LIMITATIONS}

The risks of germline gene therapy are magnified since the procedure is irreversible, and mistakes will be propagated to future generations (5). Fletcher and 


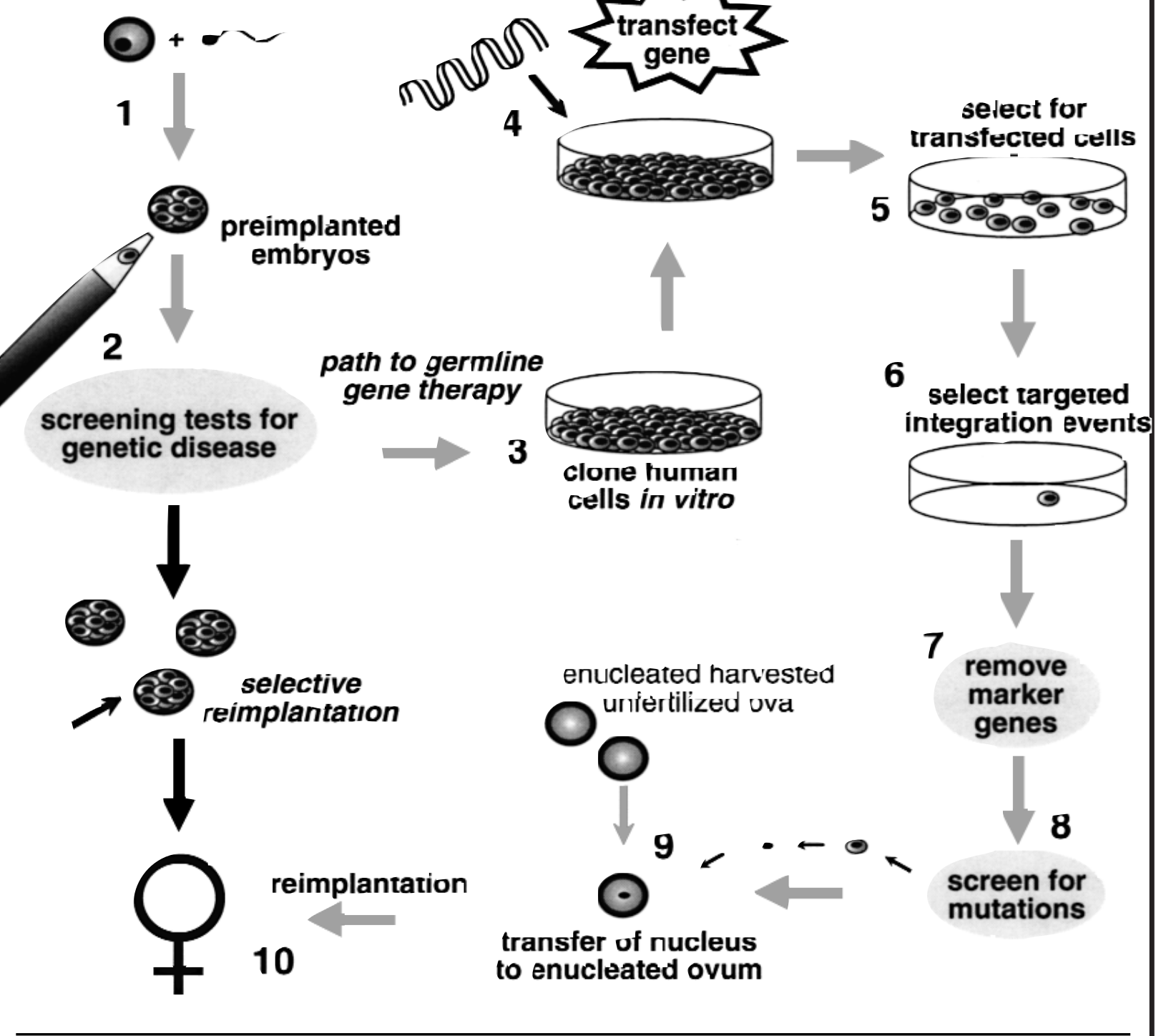

\section{Box 1. Steps Involved in a Human Germline Gene Therapy Protocol}

1. Isolation of totipotent embryonic cells at an undifferentiated stage (a preimplanted embryo within four days of conception). Step 1 is achieved either by laparoscopic flushing of oviducts to recover a naturallyfertilized ovum before implantation, or in vitro fertilization. Both these strategies are currently possible in humans, but are expensive and often require months or years of repeated attempts (1). While it may be morally preferable to genetically manipulate gametes instead of embryos, this is not technically feasible, and this strategy does not seem to be an option (2).

2. Determination of the genetic state of the embryo. "Preimplantation diagnosis" is already available on an experimental basis (3). Note that if normal embryos can be differentiated from abnormal embryos, the simplest option by far is selective reimplantation, obviating the need for genetic manipulations (Steps 3-9). On the other hand, step
2 can be skipped in rare cases (both parents homozygous for a recessive disorder, or one parent homozygous for a dominant disorder) where all embryos will be afflicted, and would not be a necessary step in "enhancement" procedures.

3. Expansion of embryonic stem cells in culture. While already achieved in mice and, more recently, in monkeys (4), this step would raise several issues if applied to humans. There is a poor success rate for establishing such cultures, and maintenance is expensive and labour-intensive. A normal karyotype has a limited lifespan in culture; in particular, second $\mathrm{X}$ chromosomes are frequently lost during growth in vitro (5), meaning that perhaps only male embryos could be successfully treated.

4. Transfer of genetic material into embryonic cells. Since millions of cells must be transfected to obtain even 
one targeted recombinant (6), mass transfection techniques will have to be employed. Available methods have limited efficiency, kill some of the target cells, and to varying degrees cause undesired DNA integration and recombination events.

\section{Selection of cells which have stably taken up the} transfected gene, present at a frequency of roughly 1 per 10000 (depending on the transfection technique). To this end, markers, such as those coding for resistance to a cytotoxic drug, are added to the transfected DNA, and after weeks of careful culturing in the presence of drug selection, clonal transfectant embryonic cell lines can be grown out. While gene supplementation tactics, addition of a normal copy of the transfected gene, which inserts into a random position in the cell's genome by illegitimate recombination, are technically the easiest way to replace the function of a defective gene, they are inherently unpredictable in their downstream effects and can only be used for somatic gene therapy. Unfortunately, current technologies only permit the addition of a supplementary gene copy (7) causing human germline gene therapy to adopt the more difficult targeted gene replacement (8).

6. Targeted gene replacement. This step represents a true genetic cure, where the deleterious DNA base pair sequence in its native chromosomal position is changed to a normal sequence that permits proper function of the gene product. However, mammalian cells favour illegitimate recombination events by a factor of at least 1000 over the homologous recombination events required for a targeted gene replacement (6). Differentiating targeted gene replacement events from illegitimate insertions is especially tedious and difficult, as in both cases cells have taken up selectable marker tags attached to the transfected DNA. Molecular biologists have devised transfection vectors that increase the proportion of targeted recombinants $(7,9)$, but only by selecting against marker-expressing illegitimate integration events; there is no way currently available to induce significantly higher absolute levels of homologous recombinations, which remain at the abysmally low rate of around 1 per 10 million cells transfected. While gene targeting techniques are probably obligatory for human germline manipulation, biological limitations make Step 6 very inefficient and difficult.

7. Marker removal. Leftover marker genes in the vicinity of the modified locus may influence neighbouring genes in undesired ways (10), and should not become part of every cell in a person, or passed on to future generations. Fortunately, molecular biologists have developed strategies to permit the removal of markers, leaving the genome completely unaltered except for the targeted sequence change (9); this requires reexpansion of the culture, and another round of drug selection.
8. Confirming genomic integrity. An embryonic cell line with the exact, desired genetic change has finally been established. However, genetic changes can occur during long term culture, and there is evidence to suggest that subtle mutations are frequently induced in regions treated by targeted homologous recombination (6). Thus, it may be necessary to recheck the genomic integrity of the cell line before attempting to reimplant an embryo. How this step could be accomplished is uncertain; it would require tedious, extensive, expensive, yet necessarily incomplete investigation. Months or years of growth in culture would be required to reach this point, but the cells should still be viable (11) for nuclear transfer.

9. Nuclear transfer. The well-publicized work of Wilmut et al., who cloned sheep from cultured cells arrested in the G0 phase of the cell cycle (11), makes step 9 theoretically possible in humans, although it has never been tried. Unfertilized ova would need to be recovered from a superovulated woman, either the mother, or a donor (who would then donate the progeny's mitochondrial DNA). With the nucleus removed, and replaced with a nucleus from Step 8, an embryo could grow, carrying the modified human genome; again, a difficult, expensive and tedious step (12).

10. Reimplantation into the mother. Embryo loss is roughly $98 \%$ (13), and remains the limiting factor in human in vitro fertilizations. Subsequent spontaneous abortion is frequent; only about $15 \%$ of couples attempting in vitro fertilization ever have a successful pregnancy (3). To increase the chance of success, multiple embryos are reimplanted simultaneously, and if multiple embryos from Step 9 "take," identical twins or triplets will result.

\section{REFERENCES}

1. Fraser FC. Preimplantation diagnosis. In: Research volumes of the Royal Commission on new reproductive technologies (vol 14). Ottawa: Minister of Government Services Canada; 1993.

2. Royal Commission on New Reproductive Technologies. Gene therapy and genetic alteration. In: Proceed with care: final report of the Royal Commission on new reproductive technologies (vol 2). Ottawa: Minister of Government Services Canada; 1993.

3. Fletcher JC, et al. Hum Gene Ther 7(13): 1605; 1996.

4. Thomson JA, et al. PNAS(USA) 92(17): 7844; 1995.

5. Robertson EJ, et al. J Embryol Exp Morphol 74:297; 1983.

6. Waldman AS. Crit Rev Oncol Hematol 12(1): 49; 1992.

7. Arbones ML, et al. Nature Genetics 6(1): 90; 1994.

8. Jeanteur P. Comptes Rendus des Seances de la Societe de Biologie et de Ses Filiales 186(5): 567; 1992.

9. Soriano P. Annu Rev Neurosci 18:1; 1995.

10. Hasty P, et al. Nature 350(6315): 243; 1991.

11. Wilmut I, et al. Nature 385(6619): 810; 1997.

12. Solter D. Nature 380(6569): 24; 1996.

13. Enquete Commission. A report from Germany - an extract from the prospects and risks of gene technology: the report of the Enquete commission to the Bundestag of the Federal Republic of Germany. Bioethics 2:254; 1988. 
Anderson (10) lament that while ethical problems should be judged by what is really possible, rooted in a specific context, this rule has rarely been followed in the debate over germline gene therapy.

The boxed section and figure on the following page describe in some detail the steps required in a human germline gene therapy procedure. Each step brings its own technical problems, and many are inefficient and costly (Box 1).

Transgenic technology, germline gene manipulation of animals, has been successfully applied in mice, pigs, sheep, and cows. However, the more tedious gene targeting procedure has only been used in mice, and it typically takes perhaps three years of concentrated effort to complete the necessary work. To begin assessing the safety and efficacy of human germline therapy, somatic cell gene therapy procedures must first be thoroughly established (15). Extensive animal studies into germline manipulation techniques, transfection vectors, and therapeutic efficacy, probably requiring decades of research, must also be completed (10). Even then, moving the studies into humans will present very challenging problems. Relatively simple questions like "do aspects of long-term cell culture, with its unnatural selection pressures, affect the person these cells may eventually become," will need to be answered specifically in humans, as animals make poor models for disorders such as mental retardation. The recent successful transgenic animal work of engineering and cloning sheep is impressive, but high failure rates, problems induced by culturing techniques and the presence of genetic markers (17) cannot be ignored.

Prior to germline therapy obtaining clinical utility, significant improvements must be made in preimplantation diagnosis, gene targeting technology, and reimplantation methods in human subjects (18). Risks and side effects of germline manipulations must be meticulously characterized, as the procedure is irreversible for the subject and its effects will extend to future generations (10). There must also, of course, exist very strong evidence for its efficacy in preventing a disease state, combined with very strong evidence that manipulations will neither compromise the subject in utero, nor adversely affect future generations (10). While future advances may overcome current technical problems, the iatrogenic risks posed by germline gene interventions will remain significant, yet difficult to predict without decades of careful human experimentation, which is considered extremely ethically problematic (9).

If the goal of germline gene therapy is the prevention of severe genetic disease in newborns, the same end can be achieved much more easily through preimplantation diagnosis and selective reimplantation (Box 1, Steps 1,2 and 10). This procedure is identical to the first and last parts of the germline therapeutic procedure, but skips entirely the in vitro culturing, transfection, selection, and nuclear transfer procedures (Box 1, Steps 3-9). Thus, human germline gene therapy presupposes development of efficient preimplantation diagnosis/selective reimplantation, and this alternative technique necessarily becomes available as a simpler, more efficient, and less dangerous option. Preimplantation diagnosis has been used to screen embryos for cystic fibrosis and several other recessive genetic diseases (10), but could equally be applied to dominant disorders. Because of inefficiencies in egg recovery and reimplantation, steps which must also be used in germline gene therapy, preimplantation diagnosis is costly and currently is only experimental (19). Available standard prenatal diagnosis by chorionic villus sampling or amniocentesis can achieve the same end, although only through second trimester abortion. Prenatal diagnosis does present a (small) risk to a potentially healthy fetus, a problem which may be circumvented through research into new diagnostic methods, directed at fetal cells shed into the maternal bloodstream (20). Thus, there is very little clinical need for germline gene therapy in the prevention of genetic disease.

Because germline gene therapy confers the same benefits as embryo selection, yet its risks will always be greater, there are few situations necessitating germline gene therapy. Two scenarios have been advanced. The first is a case where a couple, both homozygous for a serious genetic disease, wish to conceive a child free from the disease, but would not like to use donor gametes (15). Embryo screening and selection of unaffected embryos is impossible, since all zygotes conceived from this couple's gametes will carry the disease. However, if both parents have survived to reproductive age, the disease they carry cannot be one of the most severe "maladies" untreatable by other methods, ruling out many diseases commonly cited as sufficiently severe to warrant germline gene therapy (for example, LeschNyhan syndrome, Tay-Sachs disease). Even for a relatively common severe genetic disease like cystic fibrosis, the chance of two homozygotes marrying (admittedly making the assumption of independent assortment) is about 1 in four million (1), so such cases will be extremely rare. Even then, adoption, donor gametes, or somatic cell gene therapy (including fetal (19) somatic gene therapy) provide simpler and safer alternatives. DeWachter (9) suggests a second case, that of a woman who accepts preimplantation diagnosis but is morally opposed to discarding 
afflicted embryos, desiring instead a genetic cure. However, if the woman has consented to preimplantation diagnosis, she has already consented to a procedure which puts embryos at significant risk. Only a portion of recovered embryos are reimplanted at any one time, so why not put back the ones found to be free of genetic disease, and keep the rest in perpetual frozen storage, as generally happens when in vitro fertilization succeeds before all embryos have been reimplanted? The germline gene therapy procedure, as detailed in the box, will result in the death and waste of millions of totipotent embryonic cells. It is difficult to believe that anyone morally opposed to discarding an embryo would ever consent to preimplantation diagnosis, let alone germline gene therapy.

\section{FUTURE PROSPECTS}

There is no convincing case to be made that human germline gene therapy needs development for medical applications. Even optimistic projections of technical innovation imply long years of human experimentation, with significant risks and unproven benefits for subjects who cannot consent. All, these risks will be incurred to develop a procedure which will probably remain inefficient, expensive, slow, wasteful of embryos, and risky. These drawbacks can be avoided by using readily available, cheaper, simpler, faster and less-risky alternative embryo selection procedures. Scenarios where these alternatives are not applicable are more the product of hypothetical philosophy than of any foreseeable reality.

Is human germline gene therapy even worth pursuing? Medical benefits are minimal, and considering the risks for misappropriation of the technology, germline manipulations may in fact have more potential for social harm than good. Many authors have set a clear ethical line between acceptable therapeutic uses and unacceptable eugenic enhancement (9), and it is important to ask whether this ethical line can and will be respected by human societies, should the opportunity to cross it become available. Germline genetic manipulation represents an ideal technology for eugenic applications; there is no requirement for careful and difficult embryo screening (Box 1, Step 2) as part of an enhancement procedure based on presumably healthy embryos, and the simpler and already available non-targeted gene transfection is sufficient when addition of extra genetic material is the intended result of the manipulation.

Government bodies have found there to be strong support for the establishment of national regulations to prevent misuse of genetic technology (5). For example, the U.S. National Institute of Health has its
Recombinant DNA Advisory Committee carefully scrutinize, from an ethical and scientific perspective, all applications breaking new ground in somatic gene therapy technology. New protocols are approved only when they make relatively cautious, small extensions to existing procedures (12). Such bodies may well be effective in preventing the mistakes of the past, where unapproved attempts were made on patients whose consent was not clear. But limits may not work in the private sector, or across international boundaries. Exciting new technology tends to get used, even when inappropriate, despite better alternatives being available, and risks that are not fully assessed and likely underestimated (6). If human germline gene therapy techniques ever became available, the possibility remains that their use could not be constrained within a moral line allowing only therapeutic corrections of severe genetic maladies.

While rarely exploring, in depth, the detailed technological limitations of the procedure, government commissions in many first world countries have opposed research into human germline gene therapy (17). For example, the Canadian Royal Commission on New Reproductive Technologies proposed a blanket ban on both somatic cell enhancement interventions and on all germline alterations, therapeutic or otherwise (5). In fact, legislation is not needed at this point, because a de facto ban on human germline interventions is already in place, as there remain far too many technical problems to be overcome before any experimental attempts could be contemplated (10). If, for political reasons, a government ban is imposed, then, for political reasons, the scientific and medical communities should not waste effort fighting it. Transgenic animal technology should be vigorously pursued, having proven its value in studies of gene function; when combined with results from the human genome project, such work could lead to spectacular advances in genetics and biology. In contrast, human germline gene therapy is not likely ever to become an efficient or cost-effective way of dealing with genetic disease, in the face of simpler options. Most other research areas are more worthy, in the sense of offering more possible benefits to society. Other methods for preventing and treating genetic disease seem much more practical.

\section{ACKNOWLEDGMENTS}

I would like to thank Professors M. Lock (McGill Department of Social Studies of Medicine), E. Keyserlingk (McGill Centre for Medicine, Ethics and Law), G.B. Price and M. Featherstone (McGill Cancer Centre) for helpful discussions. This work was supported by studentship grants from the Medical 
Research Council of Canada and the McGill M.D./Ph.D. program.

\section{REFERENCES}

1. Enquete Commission. A report from Germany - an extract from the prospects and risks of gene technology: the report of the Enquete commission to the Bundestag of the Federal Republic of Germany. Bioethics 2:254-263; 1988.

2. Curren T. Human gene therapy. Ottawa: Library of Parliament Research Branch, 1989.

3. Anderson WF. Human gene therapy: why draw a line? Journal of Medicine and Philosophy 14:681-693; 1989.

4. U.S. Congress, Office of Technology Assessment. New developments in biotechnology—background paper: public perceptions of biotechnology. Washington, DC: U.S. Government Printing Office, 1987.

5. Royal Commission on New Reproductive Technologies. Gene therapy and genetic alteration. In: Proceed with care: final report of the Royal Commission on new reproductive technologies (vol 2). Ottawa: Minister of Government Services Canada, 1993.

6. Berger EM, Gert BM. Genetic disorders and the ethical status of germ-line gene therapy. Journal of Medicine and Philosophy 16(6): 667-683; 1991.

7. Blaese RM, Culver KW, Miller AD, et al. T lymphocytedirected gene therapy for ADA-SCID: initial results after 4 years. Science 270(5235): 475-480; 1995.

8. Caplan AL. If gene therapy is the cure, what is the disease? In: Annas GJ, Elias S, editors. Gene mapping: using law and ethics as guides. Oxford, UK: Oxford University Press, 1992.

9. DeWachter MAM. Ethical aspects of human germ-line gene therapy. Bioethics 7:166-177; 1993.
10. Fletcher JC, Anderson WF. Germ-line gene therapy: a new stage of debate. Law, Medicine and Health Care 20(1-2): 26-39; 1992.

11. Norman C. Clerics urge ban on altering germline cells. Science 220(4604): 1360-1361; 1983.

12. Latchman DS. Germline gene therapy? Gene Therapy 1(5): 277279; 1994.

13. Procter RN. Genomics and eugenics. In: Annas GJ, Elias S, editors. Gene mapping: using law and ethics as guides. Oxford, UK: Oxford University Press, 1992.

14. Appel A. Embryo research faces a renewed ban in the US. Nature 376(6538): 288; 1995.

15. Elias S, Annas GJ. Somatic and germline gene therapy. In: Annas GJ, Elias S, editors. Gene mapping: using law and ethics as guides. Oxford, UK: Oxford University Press, 1992.

16. Fletcher JC. Ethical issues in and beyond prospective clinical trials of human gene therapy. Journal of Medicine and Philosophy 10(3): 293-309; 1985.

17. Schnieke AE, Kind AJ, Ritchie WJ, Mycock K, Scott AR, Ritchie M, Wilmut I, Colman A, Campbell KH. Human factor IX transgenic sheep produced by transfer of nuclei from transfected fetal fibroblasts. Science 278(5346): 2130-2133; 1997.

18. Prior L. Somatic and germ line gene therapy: current status and prospects. In: Research volumes of the Royal Commission on new reproductive technologies (vol 14). Ottawa: Minister of Government Services Canada, 1993.

19. Fletcher JC, Ritcher G. Human fetal gene therapy: moral and ethical questions. Human Gene Therapy 7(13): 1605-1614; 1996.

20. Steele CD, Wapner RJ, Smith JB, Haynes MK, Jackson LG. Peripheral diagnosis using fetal cells isolated from maternal peripheral blood: a review. Clinics in Obstetrics and Gynecology 39:801-813; 1996.

Torsten O. Nielsen received an honours B.Sc. in biochemistry from the University of British Columbia (Vancouver, British Columbia, Canada) in 1991 before joining the McGill combined M.D./Ph.D. program. His Ph.D. thesis, Human Origins of DNA Replication: Identification, Analysis and Application, was undertaken at the McGill Cancer Centre and completed in 1996, and he graduated with an M.D.C.M. in 1997. Dr. Nielsen is now pursuing a residency in Pathology and Laboratory Medicine at the University of British Columbia. 